\title{
Future possibilities in advanced cardiac image analysis
}

\author{
Nihad Mešanović*, Elnur Smajić \\ University Clinical Center Tuzla, Tuzla, Bosnia and Herzegovina
}

Noninvasive cardiac image segmentation is an invaluable tool for the diagnosis and treatment of cardiovascular disease. Imaging technologies like magnetic resonance imaging, computed tomography, positron emission tomography, single photon emission computed tomography and ultrasound have been used extensively and have increased physicians understanding of normal and diseased heart anatomy as well as diagnostic analysis in cardiology. Future possibilities in cardiac image analysis have to include advanced segmentation methods that play a crucial role and allows for a wide range of applications, including quantification of volume, providing cardiologists computer-aided diagnosis as a second opinion, localization of pathology and image-guided interventions.

Cardiac image segmentation ${ }^{1}$ is the process of partitioning an image into regions by grouping together neighborhood pixels based on the some predefined similarity criterion. The similarity criterion can be determined using specific properties or features of picture elements (pixels) representing objects in the image. In other words, segmentation is a pixel classification technique that allows the formation of regions of interests in the image ${ }^{2}$. However, manual delineation is time-consuming and is limited by inter and intra observer variability. Also the amount and quality of imaging data that needs to be daily acquired in one or more patients is increasing. Therefore, it is crucial to develop automated, precise, and reproducible segmentation methods.

Segmentation in the field of medical imaging includes automatic detection of the coronary border in angiograms, surgical planning, measuring tumor volume and its response to therapy, automated classification of blood cells, cardiac image registration, atlas matching, heart image extraction from cardiac cine angiograms, detection of tumors, etc ${ }^{3}$. Different approaches regarding cardiac segmentation for a variety of modalities have been widely described in the literature in the past years ${ }^{4}$ and range from $2 \mathrm{D}$ methods ${ }^{5}$ to more complex, model based, and approaches ${ }^{6}$. Several software applications ${ }^{7}$ have been presented in the literature, which allows fast image processing pipelines by using a graphical user interface where different processing blocks can be interconnected.

In conclusion, the computer aided diagnosis provides fast and automatic coronary artery segmentation and visualization. Combining the $3 \mathrm{D}$ visualization of segmentation data with the clinical workflow could shorten reading time, help in diagnosis process and provide better treatment of the patient.

KEYWORDS: cardiac image segmentation, computer aided detection in cardiology.

\footnotetext{
Received: $20^{\text {th }}$ Mar 2013

*Address for correspondence: Javna zdravstvena ustanova Univerzitetski klinički centar Tuzla, Trnovac bb, 75000 Tuzla, Bosnia and Herzegovina.

Phone: +387-35-303-300

E-mail: Nihad.Mesanovic@ukctuzla.ba
}

\section{Literature}

1. Mesanovic N, Grgic M, Huseinagic H, Males M, Skejic E, Smajlovic M, Automatic CT image segmentation of the lungs with region growing algorithm. 18th International Conference on Systems, Signals and Image Processing - IWSSIP 2011, University of Sarajevo, Bosnia and Herzegovina. 2011, pp. 395-400.

2. Dhawan AP. Medical image analysis. IEEE press series in Biomedical Engineering, John Wiley \& Sons. Inc. Publications, 2003.

3. Mesanovic N, Huseinagic H, Kamenjakovic S. Disease quantification by automatic segmentation of lung CT image. 4th Congress of radiology of Bosnia and Herzegovina with international participation BHCR2011. 2011, pp. 61.

4. Suri JS. Computer vision, pattern recognition and image processing in left ventricle segmentation: The last 50 years. Pattern Anal Appl. 2000:3;209-42.

5. Jolly MP. Automatic segmentation of the left ventricle in cardiac. MRI and CT images. Int J Comp Vis. 2006;70(2):151-63.

6. Zheng Y, Barbu A, Georgescu B, Scheuering M, Comaniciu D. Four-chamber heart modeling and automatic segmentation for 3-D cardiac CT volumes using marginal space learning and steerable features. IEEE Trans. Medical Imaging. 2008;27(11):1668-81.

7. Mešanović N, Smajić E. Overview of open source software for computer aided detection in cardiology. Kardio list. 2012;7(3-4):120. 